\title{
Does Prenatal Exposure to Alcohol and Cigarette Smoking Increase Risk of Hospitalization for American Indian Infants
}

\author{
Anne Sandstrom¹, Mariah Jorda1, Bradley J. Conant', Marilyn G. Klug1, \\ Jyoti Angal ${ }^{2}$, Larry Burd ${ }^{*}$ \\ ${ }^{1}$ University of North Dakota School of Medicine and Health Sciences, Grand Forks, USA \\ ${ }^{2}$ Center for Pediatric \& Community Research, Avera McKennan Hospital \& University Health Center, Sioux Falls, USA \\ Email: *larry.burd@und.edu
}

How to cite this paper: Sandstrom, A., Jorda, M., Conant, B.J., Klug, M.G., Angal, J. and Burd, L. (2021) Does Prenatal Exposure to Alcohol and Cigarette Smoking Increase Risk of Hospitalization for American Indian Infants. Open Journal of Pediatrics, 11, 559-569.

https://doi.org/10.4236/ojped.2021.114052

Received: September 2, 2021

Accepted: October 12, 2021

Published: October 15, 2021

Copyright $\odot 2021$ by author(s) and Scientific Research Publishing Inc. This work is licensed under the Creative Commons Attribution International License (CC BY 4.0).

http://creativecommons.org/licenses/by/4.0/

(c) (i) Open Access

\begin{abstract}
Background: Prenatal exposure to alcohol and tobacco are both associated with increased risk for adverse outcomes. American Indians experience disproportionate rates of adverse birth outcomes. The Indian people living in the Great Plains Area of the Indian Health Services have increased exposure to alcohol and smoking during pregnancy. This study aims to assess the relationship between prenatal alcohol and tobacco exposure and early hospitalization in a rural Tribal Nation. Methods: We used data from the prospective Safe Passage Study on pregnancies and hospitalizations within the first year of life. The relationship between time to hospitalization and prenatal tobacco/alcohol exposure, maternal demographics, post-traumatic stress disorder and depression were evaluated. The analysis utilized Chi-square tests. Kaplan-Meier curves were used to estimate the likelihood of hospitalization during the first year of life by substance use category. Results: From a sample of 432 infants, we identified $260(60.2 \%)$ who had a hospitalization. We found no significant effect from that if mother drank, amount drank, amount smoked or if mother smoked, on the risk of hospitalization. We did identify an effect for exposure to alcohol or smoking and age to hospitalization. Exposure was associated with younger age at hospitalization. However, after controlling for mother's age, this effect was not significant. Mother's age was significant in all models of hospitalization risk from parental exposure. Discussion: Reducing prenatal exposure to tobacco and alcohol may decrease hospitalization rates for infants from this Tribal Nation, especially among young mothers.
\end{abstract}

\section{Keywords}

Hospitalization, Infants, American Indians, Alcohol, Smoking 


\section{Introduction}

The use of alcohol and tobacco during pregnancy is remarkably common. Despite well-known adverse effects from prenatal alcohol exposure, $10 \%-15 \%$ of women in the United States and Canada, report consuming alcohol during pregnancy, and 3\% report binge drinking during pregnancy [1]. Among some American Indian (AI) women drinking during pregnancy is even more prevalent with self-reported rates of $36.5 \%$ in Canada and $42.9 \%$ in the United States. Approximately $20 \%$ of pregnant AI women also report binge drinking [1].

Prenatal exposure to smoking also has a number of adverse effects and has been identified as the most important preventable cause of suboptimal pregnancy outcomes in many countries [2]. In 2010, $23.2 \%$ of women reported smoking during the 3 months before pregnancy, while 12.3\% reported smoking during pregnancy. In contrast, 55.1\% AI women reported smoking in the 3 months before pregnancy, and $26.0 \%$ reported smoking during pregnancy [3]. Prenatal exposure to smoking is associated with an increased risk of low birth weight, preterm deliveries, Sudden Infant Death Syndrome (SIDS), and preterm birth-related deaths [4].

Prenatal exposure to alcohol and cigarette smoking individually increase the risk of adverse outcomes, but dual exposure to smoking and drinking during pregnancy is often observed. A study of women who had children with fetal alcohol syndrome noted that $73.9 \%$ also smoked during pregnancy [5]. Prenatal exposure to smoking and drinking has synergistic effects and increases the risk of preterm labor, low birth weight, growth restriction, and sudden infant death syndrome [6]. These conditions are associated with an increased risk of all-cause infant mortality in the United States [7]. Prenatal exposure leading to preterm birth also increases the risk for respiratory problems, retinopathy, neonatal jaundice, cerebral palsy, and epilepsy [8].

Health disparities are common for pregnant AI women. Compared to nonHispanic white individuals, pregnant AI women are at increased risk for infant mortality and certain birth defects [9] [10]. Studies have also demonstrated that AI mothers are 1.34 times more likely to have a preterm birth compared to non-Hispanic white mothers [11]. Moreover, compared to white women, pregnant AI women are more likely to face complications including infections, postpartum hemorrhage, and gestational diabetes [12]. There are 31,329 American Indians living in North Dakota, making up $4.9 \%$ of the total population (https://www.indianaffairs.nd.gov/tribal-nations/statistics). Almost sixty percent live on reservations. AI people are the largest minority population in the state and over $40 \%$ are under the age of 20 .

While these disparities are notable throughout many geographic regions in the United States, it is important to note that there are significant geographic variations in health outcomes among AI individuals. For example, among the Indian Health Services divisions, the Great Plains Area (previously known as the Aberdeen Area) has the lowest life expectancy at birth (68.1 years), the highest 
death rates (1301.5 per 100,000 population), and the highest incidence of SIDS (264.4 per 100,000 live births) [13]. The Great Plains Area has increased rates of infant mortality (10.7\%) and alcohol-related death rates (77.0 per 100,000) [13]. A study of health disparities in North Dakota found that AI women are more likely to have increased rates of low birth weight, preterm birth, and infant mortality [10]. AI women were also more likely to report increased use of alcohol, cigarettes, and illicit drugs during pregnancy [10].

Each tribe must be considered individually in the context of its unique history, culture, traditions, and socioeconomic conditions. Previous studies have emphasized the need for further population-specific data [10]. The present study utilizes data from pregnant mothers from one Tribal Nation in this area of the United States. This Tribal Nation has over 7000 enrolled members, of whom over one-third live on the reservation. The median age for people living on the reservation was $23.4,29 \%$ were married, $72 \%$ graduated from high school and $7 \%$ had earned a bachelor's degree or higher. The median household income was $\$ 26,118$, and $47.8 \%$ lived below the poverty level, unemployment is near $50 \%$. [14].

This study examined the effect of prenatal alcohol use, smoking, or both as a risk factor for hospitalization of American Indian infants.

\section{Methods}

\subsection{Enrollment}

This study was conducted using a subset of data collected in the prospective Safe Passage Study, which is a large study of nearly 12,000 women from Northern Plains in the US and Cape Town, South Africa. In this study, we utilize data from one Tribal Nation. In keeping with the original agreement, the specific Tribal Nation will not be identified. The methods for data collection have previously been described in detail [15]. Women were enrolled in the study between six weeks gestation and up to delivery at the clinical site located on the Tribal Nation. At enrollment, the women provided consent for the components of the study, collection of personally identifiable information, and use of data and specimens for future studies. Inclusion criteria for the Safe Passage Study, "A woman is eligible if all of the following criteria are met: 1) able to provide informed consent; 2) pregnant; 3) 16 years of age or older; and 4) gestational age of at least 6 weeks, 0 days and not at the delivery admission. A woman is excluded if any of the following criteria are met: 1) planned abortion; 2) planned relocation from catchment area prior to delivery; or 3) advice against participation by a health care provider (e.g. requires additional medical care)" [15].

\subsection{Maternal Interviews}

The study was comprised of three assessment periods: prenatal, delivery/newborn, and postnatal. At the earliest prenatal visit, maternal characteristics including demographic, medical, and psychosocial information were collected. Informa- 
tion on self-reported exposures including alcohol, tobacco, marijuana, and methamphetamines was also collected. Alcohol intake was assessed via the Timeline Follow-Back method and total grams of alcohol were converted to standard drinks (14 $\mathrm{g}$ of absolute alcohol). Exposure to smoking was evaluated by asking how often the participant smoked and the number of cigarettes smoked on a typical day. Maternal depression was measured using the Edinburgh scale, and post-traumatic stress disorder (PTSD) was measured using the Harvard Trauma Questionnaire. Maternal charts from the first prenatal visit through delivery and infant charts from newborn to one year were reviewed to collect information related to growth, medications, diagnosis, clinical events, serious adverse events, and hospitalizations.

\subsection{Variables Used}

The study was comprised of three assessment periods: prenatal, delivery/newborn, and postnatal. Infant charts from newborn to one year were reviewed to collect information related to infant growth, health, and hospitalization within their first year of life. We included the data from the infant chart review data collected after age one year when completing the survival analysis (the longest follow-up time was 2657 days). Hospitalizations after the first year were not counted. Length of stay (LOS) in the hospital and the number of hospital visits during the first year were recorded.

At the earliest prenatal visit, maternal characteristics including demographic (age and employment status), medical, and psychosocial information were collected. Maternal charts provided demographics and substance use. Maternal depression was measured using the Edinburgh scale. Information on alcohol, tobacco, and marijuana was obtained by self-report. Alcohol intake was assessed via the Timeline Follow-Back method. Exposure to smoking was evaluated by asking how often the participant smoked and the number of cigarettes smoked on a typical day. Marijuana use was recorded as yes or no during pregnancy. Prenatal substance exposure was classified as: 1) any drinking during pregnancy; 2) any smoking during pregnancy; 3) marijuana use during pregnancy; and 4) a composite scale based on number of drinks, number of cigarettes, and marijuana use during pregnancy.

\subsection{Statistical Analysis}

Variables were described according to hospitalized classification, yes or no, using frequencies or means as appropriate. Chi-square tests were used to evaluate associations between categorical variables and hospitalization of the infant within one year of birth and independent t-tests for continuous variables. Proportional hazard models were used to estimate the effect of substance use on time to hospitalization. Children not hospitalized were censored at 365 days. As LOS and number of visits were skewed severely to the right, negative binomial regressions were used to test the relationships of substance use to these variables. 
Mother's age, employment, and child has been in the intensive care unit (ICU) were used as covariates in the proportional hazard and negative binomial models. SAS v 9.4 was used for the analyses.

\section{Results}

We identified $260(60.18 \%)$ children who had been hospitalized their first year and 172 (39.82\%) who had not. Table 1 shows the demographics of the study by hospitalization. Those hospitalized had slightly lower birth weight and gestation period. They were somewhat less likely to have been in ICU (73\% to 90\%). One and five-minute APGAR scores were slightly lower for those hospitalized. Mothers of hospitalized children were significantly younger (23.8 compared to 25.9 years, $\mathrm{p}<0.001)$ and more likely to be unemployed $(\mathrm{p}=0.038)$. There was minimal difference in depression between the two groups.

Hospitalized children were less likely to have mothers who used marijuana ( $51 \%$ to $79 \%, \mathrm{p}=0.043$ ). There was no significant difference in amount drank ( $\mathrm{p}$ $=0.255)$, if they drank $(\mathrm{p}=0.376)$, total cigarettes $(\mathrm{p}=0.086)$, or if they smoked $(\mathrm{p}=0.247)$ during pregnancy and hospitalization. The composite substance use score also showed no significant difference $(\mathrm{p}=0.331)$.

\section{Days to Hospitalization}

There was an average of 107.2 days till hospitalization for 280 children. Figure 1 (a) shows the box plots (median, quartiles, $10^{\text {th }}$ and $90^{\text {th }} \%$ tiles) of the days by substance use. All mothers who used substances had earlier median times of hospitalization for their children though none were significantly earlier.

Proportional hazard models were used to estimate differences in time to hospitalization between substance users while controlling for mother's age, employment, and infant ICU (Table 2).

The 93 mothers who used marijuana were not significantly different in time from those who did not use it ( $\mathrm{HR}=0.745,95 \%$ CI 0.533 to 1.041 ). Similarly, drinking, smoking, and combined substance use did not have a significant effect on time to hospitalization. Importantly, all models showed a significant effect of mother's age on the likelihood of early hospitalization.

\section{Length of Stay and Number of Visits}

The mean number of days hospitalized for 260 children was 5.79 days (SD 16.04, range 1 to 186) and the mean number of visits was 3.00 (SD 2.32, range 1 to 21). Both variables were heavily skewed right, with most children having one to two days hospitalized or one visit (Figure 1(b) and Figure 1(c)). Negative binomial regressions were used to study the relationship between substance use and hospitalization while controlling for mother's age, employment, and child's use of ICU (Table 3).

Both marijuana $(\mathrm{p}=0.049)$ and alcohol use $(\mathrm{p}=0.008)$ affected the length of stay for the infant while controlling for other variables. In this population, substance use had no significant effect on a number of hospital visits for the child. 
Table 1. Description of covariates and substance use with infant hospitalization in the first year of life 432 births.

\begin{tabular}{|c|c|c|c|c|c|c|}
\hline & \multicolumn{2}{|c|}{$\begin{array}{l}\text { Not Hospitalized } \\
(\mathrm{N}=172,39.82 \%)\end{array}$} & \multicolumn{2}{|c|}{$\begin{array}{l}\text { Hospitalized in First Year } \\
\qquad(\mathrm{N}=260,60.18 \%)\end{array}$} & \multirow{2}{*}{$\begin{array}{c}\text { Chi-Square } \\
\text { or } \mathrm{t}\end{array}$} & \multirow{2}{*}{$\mathrm{p}$} \\
\hline & $\mathbf{n}$ & $\%$ or Mean, SD & $\mathbf{n}$ & $\%$ or Mean, SD & & \\
\hline Birthweight $(\mathrm{n}=369)$ & 115 & $3.751,0.635$ & 254 & $3.693,0.613$ & 0.83 & 0.407 \\
\hline Gestation $(\mathrm{n}=390)$ & 130 & $38.77,2.04$ & 260 & $38.73,2.36$ & 0.17 & 0.862 \\
\hline Less Than 37 Weeks & 18 & 31.03 & 40 & 68.97 & 0.40 & 0.818 \\
\hline $37-42$ Weeks & 107 & 34.08 & 207 & 65.92 & & \\
\hline Over 42 Weeks & 5 & 27.78 & 13 & 72.22 & & \\
\hline \multicolumn{7}{|l|}{ Infant ICU $(n=432)$} \\
\hline Yes & 10 & 27.03 & 27 & 72.97 & 2.21 & 0.137 \\
\hline No & 162 & 94.19 & 233 & 89.62 & & \\
\hline 1 Minute Apgar $(\mathrm{n}=390)$ & 132 & $7.826,1.545$ & 258 & $7.750,1.544$ & 0.40 & 0.689 \\
\hline $1-6$ & 13 & 31.71 & 28 & 68.29 & 0.017 & 0.895 \\
\hline 7 & 16 & 32.00 & 34 & 68.00 & & \\
\hline 8 & 58 & 33.92 & 113 & 66.08 & & \\
\hline 9 & 45 & 35.16 & 83 & 64.84 & & \\
\hline 5 Minute Apgar $(n=390)$ & 132 & $8.712,1.220$ & 258 & $8.740,1.073$ & 0.23 & 0.815 \\
\hline $1-7$ & 7 & 36.84 & 12 & 63.16 & 0.001 & 0.973 \\
\hline 8 & 9 & 23.68 & 29 & 76.32 & & \\
\hline 9 & 111 & 35.13 & 205 & 64.87 & & \\
\hline 10 & 5 & 29.41 & 12 & 70.59 & & \\
\hline Mother's Age $(n=432)$ & 172 & $25.94,5.737$ & 260 & $23.850,5.456$ & 3.82 & $<0.001$ \\
\hline $16-19$ & 24 & 26.97 & 65 & 73.03 & 15.1 & 0.002 \\
\hline $20-24$ & 58 & $33.53 \%$ & 93 & $35.63 \%$ & & \\
\hline $25-29$ & 57 & 38.00 & 93 & 62.00 & & \\
\hline $30-43$ & 40 & 40.00 & 60 & 60.00 & & \\
\hline \multicolumn{7}{|l|}{ Mother's Employment $(n=432)$} \\
\hline Unemployed & 98 & 35.90 & 175 & 64.10 & 4.32 & 0.038 \\
\hline Employed & 74 & $42.77 \%$ & 85 & $32.57 \%$ & & \\
\hline Mother Depressed $(\mathrm{n}=384)$ & & & & & 0.008 & 0.928 \\
\hline Yes & 50 & 35.97 & 89 & 64.03 & & \\
\hline No & 87 & 35.51 & 158 & 64.49 & & \\
\hline \multicolumn{7}{|l|}{ Used Marijuana $(\mathrm{n}=396)$} \\
\hline Yes & 46 & 49.46 & 47 & 50.54 & 4.10 & 0.043 \\
\hline No & 97 & 56.40 & 206 & 79.23 & & \\
\hline
\end{tabular}




\section{Continued}

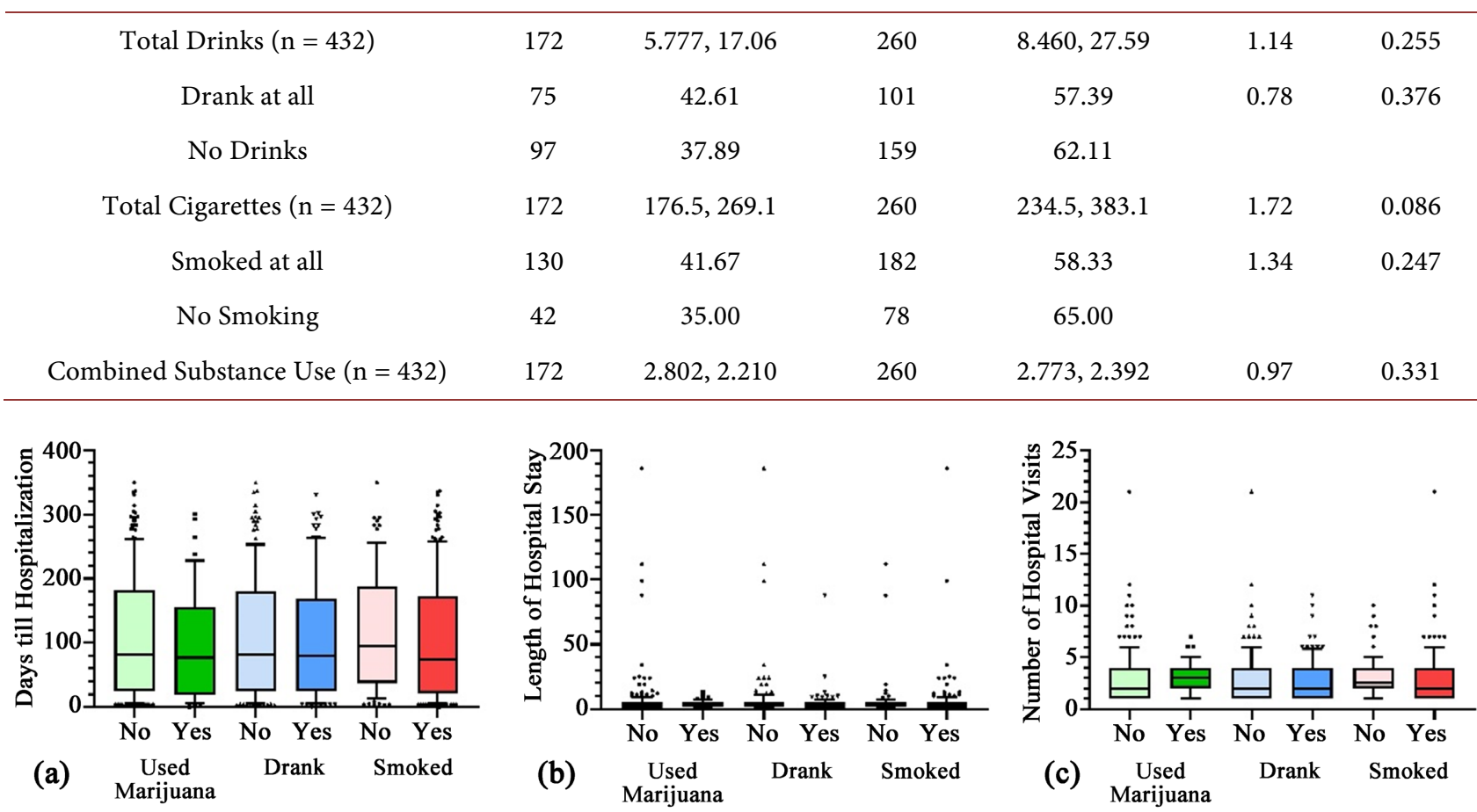

Figure 1. Box plots of hospital variables by substance use.

Table 2. Proportional hazard models predicting time to hospitalization for 432 .

\begin{tabular}{|c|c|c|c|c|c|c|}
\hline & HR & LL & UL & $\begin{array}{c}\text { Wald } \\
\text { Chi-Square }\end{array}$ & df & $\mathrm{p}$ \\
\hline Mother's Age & 0.956 & 0.934 & 0.979 & 16.9927 & 4 & 0.002 \\
\hline Infant ICU (=Yes) & 1.337 & 0.874 & 2.047 & & & \\
\hline Unemployed (=Yes) & 0.944 & 0.719 & 1.239 & & & \\
\hline Used Marijuana (=Yes) & 0.745 & 0.533 & 1.041 & & & \\
\hline Mother's Age & 0.959 & 0.937 & 0.982 & 19.7750 & 4 & $<0.001$ \\
\hline Infant ICU (=Yes) & 1.545 & 1.033 & 2.311 & & & \\
\hline Unemployed (=Yes) & 1.195 & 0.919 & 1.554 & & & \\
\hline Drank (=Yes) & 0.911 & 0.709 & 1.169 & & & \\
\hline Mother's Age & 0.959 & 0.937 & 0.982 & 20.5287 & 4 & $<0.001$ \\
\hline Infant ICU (=Yes) & 1.532 & 1.024 & 2.291 & & & \\
\hline Unemployed (=Yes) & 1.218 & 0.935 & 1.587 & & & \\
\hline Smoked (=Yes) & 0.866 & 0.662 & 1.132 & & & \\
\hline Mother's Age & 0.959 & 0.937 & 0.982 & 19.8562 & 4 & $<0.001$ \\
\hline Infant ICU (=Yes) & 1.550 & 1.036 & 2.319 & & & \\
\hline Unemployed (=Yes) & 1.208 & 0.928 & 1.572 & & & \\
\hline Combined Substance Score & 0.981 & 0.932 & 1.032 & & & \\
\hline
\end{tabular}


Table 3. Prediction of Length of stay and number of hospital visits in the first year for 260 children.

\begin{tabular}{|c|c|c|c|c|c|}
\hline Length of Stay & Estimate & S.E. & Chi-Square & $\mathrm{p}$ & $\begin{array}{c}\text { Log } \\
\text { Likelihood }\end{array}$ \\
\hline Intercept & 2.3397 & 0.3945 & 35.18 & $<0.001$ & -709.2823 \\
\hline Used Marijuana & -0.3772 & 0.1923 & 3.85 & 0.049 & \\
\hline Mother's Age & -0.0097 & 0.0148 & 0.43 & 0.514 & \\
\hline Infant ICU (=Yes) & -0.1255 & 0.2385 & 0.28 & 0.599 & \\
\hline Unemployed (=Yes) & -0.4627 & 0.1552 & 8.89 & 0.003 & \\
\hline Dispersion & 1.0873 & 0.0990 & & & \\
\hline Intercept & 2.3750 & 0.4106 & 33.46 & $<0.001$ & -711.0961 \\
\hline Smoked & -0.0124 & 0.1550 & 0.01 & 0.936 & \\
\hline Mother's Age & -0.0120 & 0.0150 & 0.65 & 0.422 & \\
\hline Infant ICU (=Yes) & -0.1887 & 0.2363 & 0.64 & 0.425 & \\
\hline Unemployed (=Yes) & -0.4960 & 0.1561 & 10.10 & 0.001 & \\
\hline Dispersion & 1.1024 & 0.0999 & & & \\
\hline Intercept & 2.4006 & 0.3923 & 37.45 & $<0.001$ & -707.6668 \\
\hline Drank & -0.3929 & 0.1472 & 7.12 & 0.008 & \\
\hline Mother's Age & -0.0088 & 0.0147 & 0.36 & 0.550 & \\
\hline Infant ICU (=Yes) & -0.2102 & 0.2340 & 0.81 & 0.369 & \\
\hline Unemployed (=Yes) & -0.4603 & 0.1536 & 8.98 & 0.003 & \\
\hline Dispersion & 1.0736 & 0.0981 & & & \\
\hline Intercept & 2.4121 & 0.3975 & 36.83 & $<0.001$ & -709.8865 \\
\hline Combined Substance Score & -0.0510 & 0.0323 & 2.50 & 0.114 & \\
\hline Mother's Age & -0.0092 & 0.0149 & 0.38 & 0.536 & \\
\hline Infant ICU (=Yes) & -0.1692 & 0.2360 & 0.51 & 0.473 & \\
\hline Unemployed (=Yes) & -0.4655 & 0.1557 & 8.94 & 0.003 & \\
\hline Dispersion & 1.0926 & 0.0993 & & & \\
\hline \multicolumn{6}{|l|}{ Number of Hospital Visits } \\
\hline Intercept & 1.7462 & 0.2981 & 34.30 & $<0.0001$ & -774.8952 \\
\hline Used Marijuana & -0.1988 & 0.1533 & 1.68 & 0.1948 & \\
\hline Mother's Age & -0.0516 & 0.0111 & 21.50 & $<0.0001$ & \\
\hline Infant ICU (=Yes) & 0.5352 & 0.2155 & 6.17 & 0.0130 & \\
\hline Unemployed (=Yes) & 0.0978 & 0.1304 & 0.56 & 0.4536 & \\
\hline Dispersion & 1.0368 & 0.1336 & & & \\
\hline Intercept & 1.8304 & 0.3090 & 35.09 & $<0.0001$ & -774.7669 \\
\hline
\end{tabular}




\section{Continued}

\begin{tabular}{|c|c|c|c|c|c|}
\hline Smoked & -0.1924 & 0.1394 & 1.90 & 0.1675 & \\
\hline Mother's Age & -0.0519 & 0.0111 & 21.81 & $<0.0001$ & \\
\hline Infant ICU (=Yes) & 0.5001 & 0.2140 & 5.46 & 0.0194 & \\
\hline Unemployed (=Yes) & 0.1331 & 0.1336 & 0.99 & 0.3191 & \\
\hline Dispersion & 1.0368 & 0.1334 & & & \\
\hline Intercept & 1.7423 & 0.3003 & 33.67 & $<0.0001$ & -775.4976 \\
\hline Drank & -0.0858 & 0.1268 & 0.46 & 0.4988 & \\
\hline Mother's Age & -0.0512 & 0.0112 & 21.09 & $<0.0001$ & \\
\hline Infant ICU (=Yes) & 0.5024 & 0.2142 & 5.50 & 0.0190 & \\
\hline Unemployed (=Yes) & 0.0842 & 0.1311 & 0.41 & 0.5210 & \\
\hline Dispersion & 1.0430 & 0.1341 & & & \\
\hline Intercept & 1.7519 & 0.3021 & 33.63 & $<0.0001$ & -775.4704 \\
\hline Combined Substance Score & -0.0181 & 0.0253 & 0.51 & 0.4739 & \\
\hline Mother's Age & -0.0514 & 0.0111 & 21.29 & $<0.0001$ & \\
\hline Infant ICU (=Yes) & 0.5102 & 0.2144 & 5.66 & 0.0174 & \\
\hline Unemployed (=Yes) & 0.1030 & 0.1313 & 0.61 & 0.4330 & \\
\hline Dispersion & 1.0434 & 0.1340 & & & \\
\hline
\end{tabular}

\section{Discussion}

After adjustment for maternal age, exposure to alcohol, smoking, or both were not significant risk factors for hospitalization of Indian infants from this Tribal Nation.

This suggests that identification of other risk factors for hospitalization is important and that additional research is warranted given the very high rates of hospitalization of infants from this Tribal Nation. The hospitalization of infants is a huge issue in this rural setting. In the United States, hospital stays pose a significant burden for families and society. The average length of hospital stay for children aged 0 - 17 years is 3.9 days, and the mean cost is $\$ 6417$ [16]. Neonates and infants are by far the most frequently hospitalized children. Infants under 1 year old account for nearly $3 / 4$ of the hospitalizations of all children under age 17 and account for more than half of the costs associated with this group. Using this cost, we estimate that in this Tribal Nation the annual cost of infant hospitalization would be 173 individuals $\times \$ 6417=\$ 1.1$ million. Over the 101 month study period, we estimate this study enrolled $36 \%$ of all infants born in this Tribal Nation. This suggests that the annual cost of care for infant hospitalizations for this Tribal Nation would exceed \$3.0 million annually. The Tribal Clinic for this rural reservation provides only week-day ambulatory care and must refer to contract facilities for inpatient care. The nearest contract facility is a 25-bed critical access hospital located over 10 miles from the clinic. The Tribal 
Clinic is over 100 miles to the location of the nearest neonatal intensive care unit, 160 miles to the nearest pediatric intensive care unit, and over 400 miles to the nearest children's hospital. Distance poses significant burdens to the family of hospitalized infants who must travel long distances to be with their child often without time for preparation. This burden is compounded by the fact that nearly $62 \%$ of the mothers in the study were unemployed and $87 \%$ had an annual income of less than $\$ 3000$. These factors make the cost of transportation and lodging even more significant. The cost of missed work and childcare for other children must also be considered.

\section{Limitations}

There are several limitations to the current study. Although the study population enrolled $36 \%$ of births for this Tribal Nation during the study period, further research with larger sample sizes would be needed to identify risk or causal factors for the high rates of infant hospitalization for this Tribal Nation. The present study was conducted using an existent data set that did not include complete information on the reason for admission or length of stay. Future studies should include these variables. While the infant medical chart reviews were used to determine which infants were hospitalized and the age at admission, much of the other data was collected via self-report and was therefore subject to recall bias. Due to the sensitive nature of many of the questions and the stigma associated with substance use and mental health, it is possible that some women chose not to disclose this information.

We found very little effect of substance use on hospitalization for the first year of an infant. Self-reported data might be a factor here, with women unlikely to report alcohol or smoking. Missing data might be a factor since most covariates couldn't be in the models due to missing values. However, including these in the model was unlikely to modify the results. Another area that may be important is the role of untreated gestational depression.

\section{Conflicts of Interest}

The authors declare no conflicts of interest regarding the publication of this paper.

\section{References}

[1] Popova, S., Lange, S., Probst, C., et al. (2017) Prevalence of Alcohol Consumption during Pregnancy and Fetal Alcohol Spectrum Disorders among the General and Aboriginal Populations in Canada and the United States. European Journal of Medical Genetics, 60, 32-48. https://doi.org/10.1016/j.ejmg.2016.09.010

[2] Cnattingius, S. (2004) The Epidemiology of Smoking during Pregnancy: Smoking Prevalence, Maternal Characteristics, and Pregnancy Outcomes. Nicotine \& Tobacco Research, 6, S125-S140. https://doi.org/10.1080/14622200410001669187

[3] Tong, V.T., Dietz, P.M., Morrow, B., et al. (2013) Trends in Smoking before, during, and after Pregnancy-Pregnancy Risk Assessment Monitoring System, United 
States, 40 Sites, 2000-2010. The Morbidity and Mortality Weekly Report (MMWR) Surveillance Summaries, 62, 1-19.

[4] Dietz, P.M., England, L.J., Shapiro-Mendoza, C.K., et al. (2010) Infant Morbidity and Mortality Attributable to Prenatal Smoking in the U.S. American Journal of Preventive Medicine, 39, 45-52. https://doi.org/10.1016/j.amepre.2010.03.009

[5] Cannon, M.J., Dominique, Y., O’Leary, L.A., et al. (2012) Characteristics and Behaviors of Mothers Who Have a Child with Fetal Alcohol Syndrome. Neurotoxicology and Teratology, 34, 90-95. https://doi.org/10.1016/j.ntt.2011.09.010

[6] Odendaal, H.J., Steyn, D.W., Elliott, A., et al. (2009) Combined Effects of Cigarette Smoking and Alcohol Consumption on Perinatal Outcome. Gynecologic and $\mathrm{Ob}$ stetric Investigation, 67, 1-8. https://doi.org/10.1159/000150597

[7] Kochanek, K.D., Murphy, S.L., Xu, J., et al. (2016) Deaths: Final Data for 2014. National Vital Statistics Reports, 65, 1-122.

[8] Platt, M.J. (2014) Outcomes in Preterm Infants. Public Health, 128, 399-403. https://doi.org/10.1016/j.puhe.2014.03.010

[9] Aggarwal, D., Warmerdam, B., Wyatt, K., et al. (2015) Prevalence of Birth Defects among American-Indian Births in California, 1983-2010. Birth Defects Research Part A: Clinical and Molecular Teratology, 103, 105-110. https://doi.org/10.1002/bdra.23341

[10] Danielson, R.A., Wallenborn, J.T., Warne, D.K., et al. (2018) Disparities in Risk Factors and Birth Outcomes among American Indians in North Dakota. Maternal and Child Health Journal, 22, 1519-1525.

https://doi.org/10.1007/s10995-018-2551-9

[11] Hwang, M., Shrestha, A., Yazzie, S., et al. (2013) Preterm Birth among American Indian/Alaskan Natives in Washington and Montana: Comparison with Non-Hispanic Whites. Maternal and Child Health Journal, 17, 1908-1912.

https://doi.org/10.1007/s10995-012-1215-4

[12] Cabacungan, E.T., Ngui, E.M. and McGinley, E.L. (2012) Racial/Ethnic Disparities in Maternal Morbidities: A Statewide Study of Labor and Delivery Hospitalizations in Wisconsin. Maternal and Child Health Journal, 16, 1455-1467. https://doi.org/10.1007/s10995-011-0914-6

[13] U.S. Department of Health and Human Services, Indian Health Service, and Office of Public Health Support Division of Program Statistics (2012) Regional Differences in Indian Health. 1-122.

[14] Conway, P., Boeckel, J., Lawrence, C., et al. (2016) Spirit Lake Nation Comprehensive Community Assessment 2015. Fort Totten.

[15] Dukes, K.A., Burd, L., Elliott, A.J., et al. (2014) The Safe Passage Study: Design, Methods, Recruitment, and Follow-Up Approach. Paediatric and Perinatal Epidemiology, 28, 455-465. https://doi.org/10.1111/ppe.12136

[16] Witt, W.P., Weiss, A.J. and Elixhauser, A. (2014) Overview of Hospital Stays for Children in the United States, 2012. HCUP Statistical Brief \#187. Agency for Healthcare Research and Quality, Rockville, MD.

https://www.hcup-us.ahrq.gov/reports/statbriefs/sb187-Hospital-Stays-Children-20 12.pdf 